\title{
Making sense of flash drought: definitions, indicators, and where we go from here
}

\author{
Joel Lisonbee $_{1,3}$, Molly Woloszyn $_{1}$, Marina SkUManich $_{2}$
} Affiliation:

1. NOAA/National Integrated Drought Information System, and Cooperative Institute for Research in the Environmental Sciences (CIRES), University of Colorado Boulder, Boulder, Colorado

2. NOAA/National Integrated Drought Information System, and University Corporation for Atmospheric Research (UCAR), Boulder, Colorado

3. University of Southern Queensland, Toowoomba, QLD, Australia

\begin{abstract}
The topic of "Flash Drought" is rapidly gaining attention within both the research and drought management communities. This literature review aims to synthesize the research todate and provide a basis for future research on the topic. Specifically, our review is focused on documenting the range of definitions of "flash drought" being proposed in the research community. We found that the term first appeared in the peer-reviewed literature in 2002, and by 2020 has become an area of active research. Within that 18-year span, "flash drought" has been given 29 general descriptions, and 20 papers have provided measurable, defining criteria used to distinguish a flash drought from other drought. Of these papers, 11 distinguish flash drought as a rapid-onset drought event while eight distinguish flash drought as a short-term or short-lived, yet severe, drought event and one paper considers flash drought as both a short-lived and rapid onset event. Of the papers that define a flash drought by its rate of onset, the rate proposed ranges from 5 days to 8 weeks. Currently, there is not a universally accepted definition or criteria for "flash drought," despite recent research that has called for the research community to adopt the principle of rapid-intensification of drought conditions.
\end{abstract}

\section{Motivation and Methodology}

Flash drought has been the topic of scientific research since 2002. Research on this topic has recently increased, with a significant rise in the number of publications starting about 2013 (Figure 1). As of July 2020, there have been over 50 publications wholly devoted to the topic and at least 142 others that mention the term "flash drought" in relation to other topics. ${ }^{1}$ Within these publications, unique defining criteria have been applied to flash drought at least 20 times. Currently, there is not a universally accepted definition or criteria for flash drought, though the principle of rapid onset or intensification that ends in drought is generally applied (Otkin et al. 2018a).

The motivation for this paper is to synthesize this broad range of research, highlight some of the questions and incongruities that exist within the literature to date, and provide a basis for future research on flash drought. We hope this paper will serve as a resource for other researchers as they frame research questions to improve our physical understanding of this phenomenon. We do not attempt to critique the flash drought definitions provided in the literature thus far. Instead, our intent for this paper is to support more discussion within the literature - and the research community more broadly_regarding what are the "right" ways, and perhaps more importantly, most useful ways, to characterize flash drought.

We have focused this literature review of flash drought research on the use and definition of the term "flash drought" in the literature to date. Following the methodology of Pickering and Byrne (2014), this review began with an online search via Scopus (www.scopus.com) for any peer-reviewed journal publications that included the words "flash drought" in the article title, abstract, or keywords. This

${ }^{1}$ As detailed below, we are only including 86 of these publications in the reference list herein.

Corresponding Author: Joel Lisonbee. Email: joel.lisonbee@noaa.gov

Journal of Applied and Service Climatology, Volume 2021, Issue 001, DOI: doi.org/10.46275/JOASC.2021.02.001 


\section{Number of Publications per Year that Define/Describe or Mention Flash Drought \\ - Define/Describe - Mention}

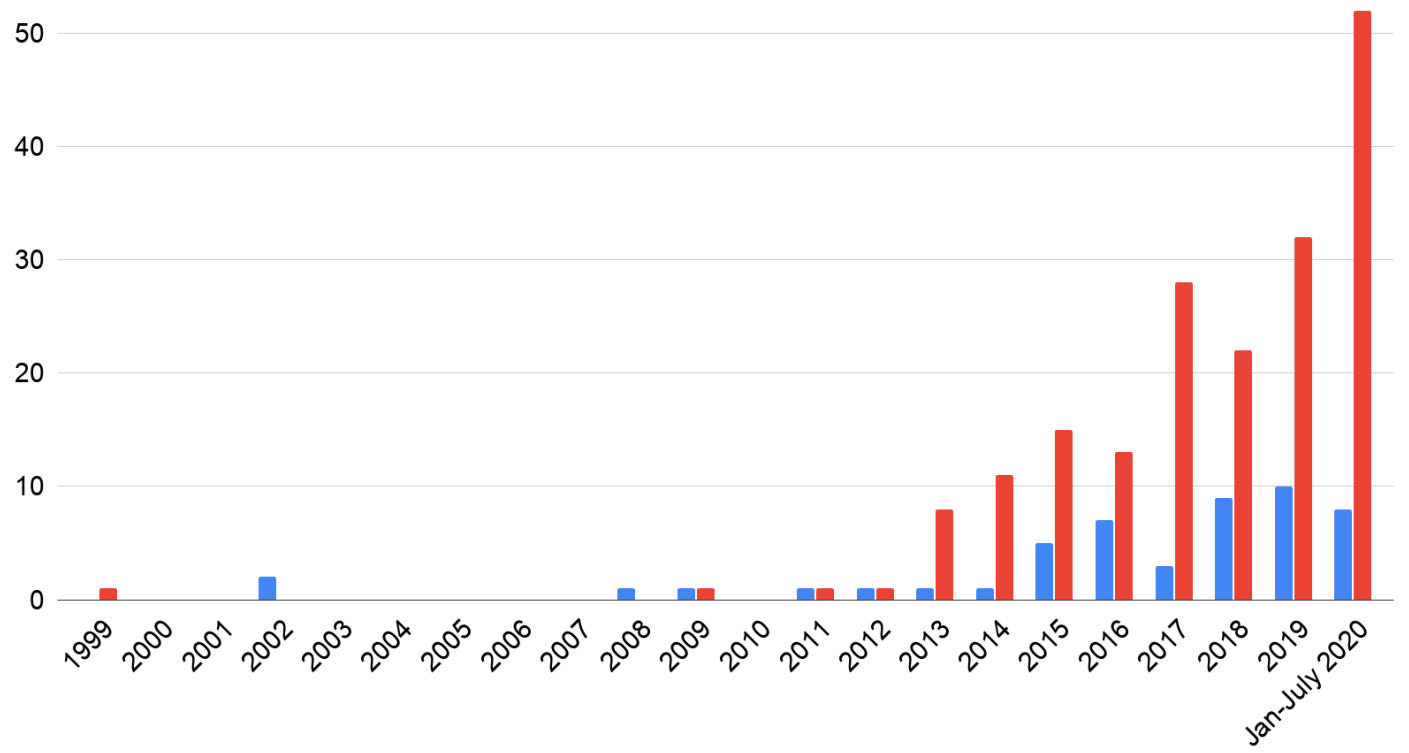

Year

FIGURE 1: Number of publications each year that either provided a definition or description of flash drought (blue) or that simply mentioned the term "flash drought" without providing a description or definition (red).

search produced 52 unique results (as of July 2020). Twenty more papers were added to these results based on papers referenced within any of the articles identified (including each newly-added paper) and further input from subject matter experts. Of these 72 total publications, nine simply mentioned the term "flash drought" without providing any further description or definition and are not included herein. The remaining 63 citations included 60 refereed journal publications, one magazine article, one book chapter, and one conference paper.

One of the motivations for limiting a search to the article title, abstract and keywords is to identify articles that are dedicated to the topic of flash drought. However, one limitation to this approach is that it overlooks articles that use the term "flash drought" within the text but may not have been dedicated to the topic. Since we are interested in the use and definitions of the term, whether the paper was devoted to the topic or not, we chose to supplement our Scopus search with an online search using Google Scholar. ${ }^{2}$ This produced 644 search results (through July 2020), which we then refined to include only peer-reviewed journal publications (374 results). The results were further filtered to remove spurious search results - those that did not actually include the term "flash drought" in the text (148 results), papers that simply mention the term "flash drought" but do not provide any further description or definition (142 results), or papers that had already been referenced from the Scopus search (59 results). This left us with 23 articles that were added to the literature review, giving a total of 86 articles.

These results were then sorted according to how the term "flash drought" was used. We looked for whether they provided a general description or a measurable definition based on set criteria and if they focused on a specific drought event (e.g., Central U.S. 2012 or Northern Great Plains U.S. 2017). After identifying some general patterns in the definitions used, for perspective and completeness we performed one final search in Scopus for papers that - while not using the term "flash drought" per se, were focused on concepts or events that share similar physical characteristics with those considered "flash droughts." This final search (using Scopus in early August 2020) combined the terms "rapid onset" + "drought," "rapid development" + "drought," "rapid intensification" + "drought," "short-term" + "drought,"3 and "short-duration" + "drought." This produced 203 total results, including 167 irrelevant results (e.g., economics, engineering, botany, etc.), 32 duplicate results to the "flash

${ }^{2}$ Google scholar picks up any journal, university or research organization publications that contains the search phrase, which includes theses, newsletters, curriculum vitae, etc.

${ }^{3}$ The search "short-term" + "drought," produced 2,541 results, so in this case we refined our search to also include "flash drought" somewhere in the text. 
drought" search, and three papers that are included in the final literature review.

This study contains a few limitations that should be noted. One limitation is that the search results were not sorted by region or location. Therefore, the regional differences of flash drought definitions will not be explored here. We also did not compare definitions by the authors' intent (e.g., was a definition intended to measure an event or predict an event, etc.). Both of these are topics for future research. Another key limitation includes the timeliness of the search results: this literature review reflects a snapshot in time as of July/August 2020. Given that flash drought is a very active topic of research, it is likely that several more papers have been published on the topic since our searches were conducted; any such papers would not be included herein.

\section{A Brief Timeline of Flash Drought Research Highlights}

\subsection{First References}

In 1999, R. Showstack authored a piece for EOS, Transactions ${ }^{4}$ titled, US Federal Government Tries to Get Ahead of the Curve with Drought Planning, in which prominent physical scientists were interviewed about drought. Showstack (1999) points to the slow onset of drought compared to more dramatic and sudden weather events and states "Droughts receive less attention because they are slow-moving disasters... There is no such thing as a flash drought, for instance, and droughts edge up without lightning bolts or tremors that people experience directly" (Showstack, 1999, p. 365).

Showstack (1999) notwithstanding, the term "flash drought" began showing up in the published literature only three years later. First, in January 2002 by Peters et al. (2002) - a paper on the derivation and utility of the Standardized Vegetation Index (SVI) - that points to the rapid intensification of drought across the southern High Plains in August and September 2000 and says, "the term to describe this was 'flash drought' because of the combination of no precipitation and very high temperatures" (Peters et al. 2002, p. 73), likely alluding to discussions about the event that were occurring outside of the published literature at the time. The term appeared again in August 2002 in the foundational paper on the U.S. Drought Monitor by Svoboda et al. (2002), where "flash drought" was mentioned in a general reference to rapidly intensifying drought conditions.

Both Svoboda et al. (2002) and Peters et al. $(2002)^{5}$ have been referenced as the first use of the term "flash drought."
Ten papers specifically cite the Svoboda et al. (2002) study in reference to the term "flash drought" (see Appendix 1 for a list of these papers). ${ }^{6}$ Peters et al. (2002) was referenced twice, these were by Twidwell et al. (2014) and Lee and Gill (2015).

\subsection{First General Definitions}

The earlier references to flash drought were general in their description. For example, Svoboda et al. (2002) describes flash drought as "rapid crop deterioration due to the adverse effects of a severe heat wave and short-term dryness, leading to a rapid onset of drought and associated impacts..." (Svoboda et al. 2002, p. 1184). The first place to offer a definition of flash drought (and specifically call it a definition) was a conference presentation at the AMS 22nd Conference on Hydrology in 2008. Here Senay et al. (2008) defined flash drought as "a short-term, yet severe [drought] event, characterized by moisture deficits and abnormally high temperatures" (Senay et al. 2008, Abstract). The Senay et al. (2008) drought definition has been referenced directly five times by subsequent authors (See Appendix 1) in the use or definition of the term "flash drought."

\subsection{First Paper to Define Flash Drought Using Indicator Values and a Defining Criterion}

Hunt et al. (2009) was the first paper to use a set of criteria to objectively determine a flash drought. With a reference to Senay et al. (2008), they defined a flash drought as "a severe, short-term [drought] event characterized by moisture deficits and abnormally high temperatures" (Hunt et al. 2009 , p. 757). Hunt et al. (2009) further add that "a flash drought is the result of a synoptic meteorological pattern where potential ET (evapotranspiration) greatly exceeds precipitation for a period no less than 3 weeks such that available water in a previously moist $(0-50 \mathrm{~cm})$ soil profile decreases by more than 50\%" (Hunt et al. 2009, p. 757). This definition has been cited at least four times, including by Mo and Lettenmaier (2015) before they proposed a flash drought definition based on heat waves (see Sections 3.2 and 3.4).

\subsection{First Paper to Solely Focus on Flash Drought}

The first paper solely devoted to the topic of flash drought was Otkin et al. (2013), which examined the characteristics of the following four "rapid-onset droughts": Oklahoma and Arkansas in late summer 2000; Indiana and Ohio in early summer 2007; Southeast Wisconsin in summer 2002; and Oklahoma and Arkansas in summer 2011. This paper used the terms "rapid-onset drought" and "flash

${ }^{4}$ EOS, Transactions was a weekly magazine of Earth science published by John Wiley \& Sons for the American Geophysical Union (now available online only at eos.org).

${ }^{5}$ Svoboda was also a co-author on the Peters et al. (2002) paper.

${ }^{6}$ It should be noted that a total of 63 of the papers included in this review reference Svoboda et al. 2002, but usually in reference to the US Drought Monitor, rather than to the term "flash drought." 
drought" interchangeably. This paper demonstrated that the Evaporative Stress Index (ESI) is effective in providing early warning of flash drought events. While they did not explicitly define flash drought, they referred to Mozny et al. (2012) in their description of flash drought.?

\subsection{Flash Drought Research and the 2012 Drought}

Between 2002 and 2012 the literature was relatively quiet on the topic of flash drought. It is possible that there were papers published on the topic during this time that simply did not use the term "flash drought" but rather stayed within the accepted terminology of the time. Two possible examples of this are Fowler and Kilsby (2002) and Illston et al. (2004). Fowler and Kilsby (2002) mention rapid onset of drought in the Yorkshire region of the UK, but do not use the term "flash drought." This paper was the only one found between 2002 and 2012 using any of the additional search terms ("rapid onset" + "drought" in this case). Illston et al. (2004) was found as a reference in Hunt et al. (2014). This paper examines rapid changes in the soil moisture profile in Oklahoma, USA, before and after the 2000 drought, but they do not call it a "flash drought." Any other similar papers using slightly different terms than those we searched for might not have shown up in our literature search and would not be included in this review.

The rate of flash drought publications increased after 2012 (see Figure 1). One reason for this increase is the extreme drought over the central US during 2011 and 2012. During this time, the term seemed to be picked up by both the media and the scientific community in the United States (Otkin et al. 2018a). According to many publications, the 2012 drought in the US Central Plains was a quintessential flash drought ${ }^{8}$ and has been used as a case study by many (Hoerling et al. 2013, 2014; Kumar et al. 2013; AghaKouchak 2014; Otkin et al. 2014, 2015b; Behrangi et al. 2015; Mo and Lettenmaier 2015; Wang et al. 2015; Sun et al. 2015; McNider et al. 2015; PaiMazumder and Done 2016; Otkin et al. 2016; Lorenz et al. 2017a,b; Hao et al. 2017; Rupp et al. 2017; Yang et al. 2018; Yan et al. 2018; Jin et al. 2019; Sun et al. 2019; Basara et al. 2019) or as a flash drought standard against which to compare other droughts (He et al. 2019). While the literature shows there had been droughts prior to 2012 that are now considered to be flash droughts [e.g., 1988 in the north central US (Trenberth et al. 1988), 1999 in Nebraska (Hunt et al. 2009), Southeast Wisconsin in summer 2002 (Otkin et al. 2013), 2000 in the Southern US (Peters et al. 2002; Otkin et al. 2013), Indiana and Ohio in early summer 2007 (Otkin et al. 2013), and Oklahoma and Arkansas in summer 2011 (Otkin et al. 2013)], the 2012 event certainly attracted researchers' attention to the topic.

\section{Definitions}

Flash drought has been defined or described in at least 49 different ways, although several definitions ${ }^{9}$ are closely related or add qualifiers to previously proposed definitions. This section documents all of these definitions or descriptions and the criteria used by each definition. Where a definition is used in multiple papers, we include only its first instance, and note who refers to that definition in subsequent research, ${ }^{10}$ although we include those papers where the definitions were adapted in some way. We chose to group these definitions into the following categories: (1) general definitions that provide a qualitative description of flash drought but provide neither criteria nor thresholds to measure or distinguish flash drought events; (2) definitions based on the rate of onset; (3) definitions based on duration of the drought event or that, by nature of the criteria used, can distinguish a flash drought as one with a short duration; (4) definitions based on both the duration and the rate of onset to identify a flash drought (one paper).

\subsection{General Definitions or Descriptions}

Twenty-nine papers provided a general description of flash drought (Appendix 1). While some papers may describe flash drought in terms of rate of onset/intensification or duration, they do not provide specific thresholds that could be used to distinguish flash droughts.

One notable inclusion here is Otkin et al. (2018a), which provided a review and assessment of flash drought science up to 2018. The authors proposed that flash drought is "a subset of all droughts that are distinguished... by their unusually rapid rate of intensification" (Otkin et al. 2018a, p. 914). However, it did not specify how rapid the rate must be to be considered "unusual;" i.e., they did not provide a definition based on thresholds of an indicator(s). Rather, the authors proposed a set of guiding principles that should be considered when examining flash drought. A criteria-based definition was proposed by Christian et al. (2019a) based on the recommendations made by Otkin et al. (2018a) and will be discussed briefly in the next section.

The 29 general definitions listed in Appendix 1 can be categorized in the following way:

- 15 described flash drought as a rapid onset or

${ }^{7}$ In their description of flash drought, Mozny et al. (2012) in turn drew from Hunt et al. (2009) and referred to Senay et al. (2008), which was the first research to offer a definition of the term, as noted above in Section 2.2.

${ }^{8}$ One exception is McEvoy et al. (2016) which demonstrates the application of the Evaporative Demand Drought Index (EDDI) for detecting and monitoring flash drought and challenges the notion that 2012 should be considered a flash drought, at least over central lowa.

${ }^{9}$ While we use the word "definition," in some instances the authors only provide a description of the term "flash drought." We are including these papers here for completeness.

${ }^{10} \mathrm{~A}$ full list of the papers identified are included in the references section. 
intensification drought event (Anderson et al. 2011; Otkin et al. 2014; Sun et al. 2015; Anderson et al. 2016; Brown et al. 2016; Hobbins et al. 2016, 2017; Cook et al. 2018; Yao et al. 2018; Otkin et al. 2018a; Lorenz et al. 2018; Gerkin et al. 2018; Hoell et al. 2019; Jin et al. 2019; Trnka et al. 2020).

- Ten described flash drought as a short-term drought event (Senay et al. 2008; Hunt et al. 2014; Yuan et al. 2015; Cammalleri et al. 2016; Orbringer et al. 2016; Sanchez et al. 2016; Vogt et al. 2018; Haile et al. 2020; H. Zhang et al. 2019; Zhang et al. 2020).

- A few hard-to-categorize papers include:

- Stojanovic et al. (2020) which described flash drought as having both a sudden onset and a short duration

- Svoboda et al. (2002) which describes "...shortterm dryness, leading to a rapid onset of drought" (p. 1184)

- Peters et al. (2002) and Han et al. (2019) both describe flash drought as a combination of no precipitation and very high temperatures without any indication of the rate or duration of the event

\subsection{Rate vs. Duration}

As mentioned above, we could have grouped these definitions in various ways, but the literature includes a subtle debate about whether flash drought should be defined by the rate of onset/intensification or the duration of the drought event, and we have chosen this grouping to bring this debate to the forefront.

The Senay et al. (2008) definition references "short-term, yet severe" events that last at least three weeks but are not required to last longer than that. This idea of a "short-term" drought was supported by Mo and Lettenmaier $(2015,2016)$ who proposed that there are two types of flash drought, a "heat wave flash drought" and a "precipitation deficit flash drought." While the precise definitions proposed by Mo and Lettenmaier $(2015,2016)$ do not have a duration requirement, the nature of their proposed definition relying on a heat wave means that these events will be short-lived. Therefore, they conclude, "One feature that distinguishes flash droughts from longer meteorological and agricultural droughts is that flash droughts generally do not persist because $\mathrm{T}_{\text {air }}$ anomalies tend not to be persistent. For heat wave flash droughts, most events only last for one to two pentads." (Mo and Lettenmaier 2016, p. 1173).

The Otkin et al. (2018a) review paper on the topic weighed in heavily on this debate, stating: "Here, we have proposed that the definition for 'flash drought' should inherently focus on its rate of intensification rather than its duration, with droughts that develop much more rapidly than normal being identified as flash droughts" (Otkin et al. 2018a, p. 914) Under this definition, even droughts that persist for several years may be considered a flash drought, (e.g., Southeast Australia 2017-2020 drought, see Nguyen et al. 2019).

\begin{tabular}{cc}
\hline TABLE 1. Comparison of onset rates from papers that defined flash \\
drought as a "rapid-onset" event.
\end{tabular}

\subsection{Rate of Onset/Intensification Definitions}

Eleven papers in our review define flash drought by its rate of onset or intensification that are tied to specific thresholds of various indicators (Appendix 2).

The rate of flash drought development depends on the definitions and criteria used in the publications, with onset rates ranging from five days to eight weeks. Table $1 \mathrm{com}-$ pares the onset rates for each of the definitions listed in Appendix 2.

\subsection{Short-Duration Drought Events}

Eight papers provided a set of criteria that defined a flash drought to be one that is short-lived (Appendix 3). While only two of the definitions listed in Appendix 3 includes short-duration as a defining criteria of a flash drought (Hunt et al. 2009; Li et al. 2020c), they all consider flash drought to be short-term drought events by nature of the criteria used. Two examples illustrate this: M. Zhang et al. (2019) defined flash drought in terms of rainfall deficit at a specific time of the year at Shanchuan, China; a "flash-drought event is defined as when the monthly (July or August) rainfall is less than $100 \mathrm{~mm}$ " (M. Zhang et al. 2019, p. 2). The second example is from Mo and Lettenmaier $(2015,2016)$ where they require a flash drought to be associated with a heat wave. Mo and Lettenmaier (2016) acknowledge that "Because heat waves do not persist, most flash droughts only last one or two pentads" (Mo and Lettenmaier 2016, p. 1183). Hence, we have included these, and similar definitions (Zhang et al. 2017; Yuan et al. 2018; Wang and Yuan 2018) in the short-duration drought event category.

As an aside, most authors who considered flash drought to be a short-term drought event also considered flash drought to be a subset of agricultural droughts. Hunt et al. (2014) and Svoboda et al. (2002) both mention agricultural impacts in their description of flash drought, especially when the short-term dryness corresponds with sensitive times in a crops' development. Mo and Lettenmaier (2015) described a Heat Wave Flash Drought (see Appendix 3 for a description) as agricultural drought in nature. Mo and Lettenmaier 
(2016), when comparing the Heat Wave Flash Drought and the Precipitation Deficit Flash Drought (see Appendix 3) explain, "Both are manifested by [soil moisture] deficits that cause damage to crops. In that sense, both are agricultural droughts" (Mo and Lettenmaier 2016, p. 1181). Zhang et al. (2017) state that "soil moisture deficit is an important indicator of flash drought, and soil moisture is the proximate determinant of agricultural drought, therefore, flash drought is the category of agricultural drought" (p. 167). Wang and Yuan (2018) cite Mo and Lettenmaier (2015) when they write "flash drought is an agricultural drought in nature" (Wang and Yuan, 2018, p. 1480).

\subsection{Rapid Onset and Short Duration Drought Definition}

There was one paper that included both a rate of onset and short-duration criteria to identify a flash drought (Appendix 4). Li et al. (2020a) used a standardized evapotranspiration deficit index (SEDI) to identify flash drought using the following three criteria: (1) the duration is longer than five pentads but shorter than twelve pentads; (2) the instantaneous intensification rate of the cumulative SEDI is at or below the $25 \%$ of cumulative distribution frequency of the change in the cumulative SEDI during flash drought development; (3) the average instantaneous intensification rate during flash drought development phase is at or below the $40 \%$ of cumulative distribution frequency of the change in the cumulative SEDI during flash drought development.

\section{Indicators Used in Flash Drought Definitions}

The indicators used in flash drought definitions vary by paper. In this section we have grouped flash drought criteria by indicator used, which also may give an indication of the type of drought described (meteorological, agricultural, hydrological, socioeconomic and ecological; see Otkin et al. 2018a). We will first look at which papers rely upon the US Drought Monitor changes (Svoboda et al. 2002), as the US Drought Monitor is produced through expert examination of a myriad of data sources. We then will look at the indicators used by other papers.

\subsection{The US Drought Monitor in Flash Drought Definitions}

There were four papers that defined flash drought using category changes in the US Drought Monitor as a way to identify a flash drought. These are included in Table 2 (these are also listed among the definitions grouped in Appendices 1, 2 and 3). Even among these papers, the rate of change differs by definition. Pendergrass et al. (2020) proposed a two-category change in two weeks, while Chen et al. (2019) also proposed a two-category change but over four weeks. Lorenz et al. (2018), through some experimentation, considered "rapid onset" to mean any change toward drought within 2, 4, or 6 weeks. Ford et al. (2015) looked for a three-category change toward drought in eight-weeks or less.

Not included in Table 2, but still notable, are Anderson et al. (2013) and Otkin et al. (2015b). Anderson et al. (2013) did not use the US Drought Monitor in their definition of flash drought but used the US Drought Monitor as a "standard of truth" as they compared hydrologic indicators during drought periods. Otkin et al. (2015b) did not use the USDM to define flash drought, but observed that "...according to the U.S. Drought Monitor (USDM), many locations across the central United States during the 2011 and 2012 flash droughts experienced up to a three-category increase in drought severity in only one month, meaning that areas that were drought free at the beginning of the month were characterized by severe to extreme drought conditions by the end of the month" (Otkin et al. 2015b, p. 1073).

\subsection{Other Indicators Used}

We have documented the types of indicators that have been used to define and measure flash drought (Appendix 5). Out of brevity, we have limited our list of indicators to only those used to define flash drought (i.e., not considering other drought analysis that may have been done in those papers or subsequent research that referenced those definitions, see Appendices 2, 3, and 4). Soil moisture data is used in 11 definitions, evapotranspiration is used eight times, precipitation is used seven times and air temperature is used in six definitions. Three definitions use an index for atmospheric evaporative demand (EDDI, ESI and ESR), satellite-based vegetation land-surface temperature, and precipitation-evaporation-based drought indices (SPEI) are each used once (see Appendix 5). Some of the indicators

TABLE 2. Papers that use the US Drought Monitor to identify flash drought.

Reference Specific criteria

Pendergrass Flash drought definition 2 (application: et al. (2020) US operations): two-category change in the USDM in 2 weeks, sustained for at least another 2 weeks

Chen et al. "[W]e define a flash drought event as a (2019) drought event with greater than or equal to two categories degradation in a four-week period based on USDM." (p. 2)

Lorenz et al. Generally: if the USDM is more intense in (2018) 2, 4, or 6 weeks, then they consider this a rapid-onset to the drought situation.

Ford et al. "We define a flash drought event in the US (2015) Drought Monitor record as three category or more increase in drought severity over 8 or less weeks."(p. 9793) 
used to identify flash drought are composite-indices that are formed from multiple elements (e.g. the SPEI). When considering only the base elements of indicators and indices (e.g. SPEI is separated into precipitation and evaporation), Figure 2 shows that evaporation/evapotranspiration (12 times) and soil moisture (11 times) are the most frequently used indicators of flash drought. These seem logical metrics when measuring flash drought considering that by most of the definitions considered, flash drought represents a rapid change in the available water in the landscape (whether those changes persist or not).

Only one study used SPEI (Noguera et al. 2020) and none of the definitions use the Standardized Precipitation Index (SPI) to define flash drought. Zhang et al. (2017, p. 163) claim that these indices are not appropriate for flash drought measurement "due to the relatively untimely response to monthly input data versus immediate prevailing weather conditions" [note that Zhang et al. (2017) considered flash drought to be those that persist for a short duration - days to weeks]. Otkin et al. (2013) explains that precipitation-based drought indices, such as the SPI, can miss a flash drought because precipitation deficits are only one factor contributing to their development. Flash droughts can occur even when the SPI indicates only moderate precipitation deficits. Otkin et al. (2013) further explains that the Palmer Drought Severity Index (Palmer 1965) also may not be appropriate for flash drought detection. While it uses both precipitation and temperature observations, it is more effective at identifying long-term drought conditions developing over a period of several months and may be overly sensitive to temperature effects (Otkin et al. 2013). However, both the SPI and SPEI were used by Hunt et al. (2014) in their analysis of "rapid onset drought" which demonstrated that both the 1-month SPI and the 1-month SPEI were quite sensitive to the onset of the flash drought. Hunt et al. (2014) used the Svoboda et al. (2002) description as their definition of flash drought.

There were a few studies that used indicators and indices to examine some characteristics of flash drought but did not use these as defining criteria nor categorical thresholds for flash drought identification. Most of the indicators used were also used by the papers listed in Appendix 5. A few other indicators, not listed above, include: crop condition data, cloud cover, 10-m wind speed, dewpoint depression (Otkin et al. 2013), a rapid change index for ESI, the SPI and total column soil moisture (Otkin et al. 2015a), a vegetative drought response index, dew point temperature (Otkin et al. 2016), a lower tropospheric humidity index, a convective triggering potential-similar to CAPE (Gerken et al. 2018), various remote sensing techniques including NASA's Soil Moisture Active Passive (SMAP) mission data and Satellite Solar-induced chlorophyll fluorescence (Yan

\section{Indicators Used to Define Flash Drought in the Literature}

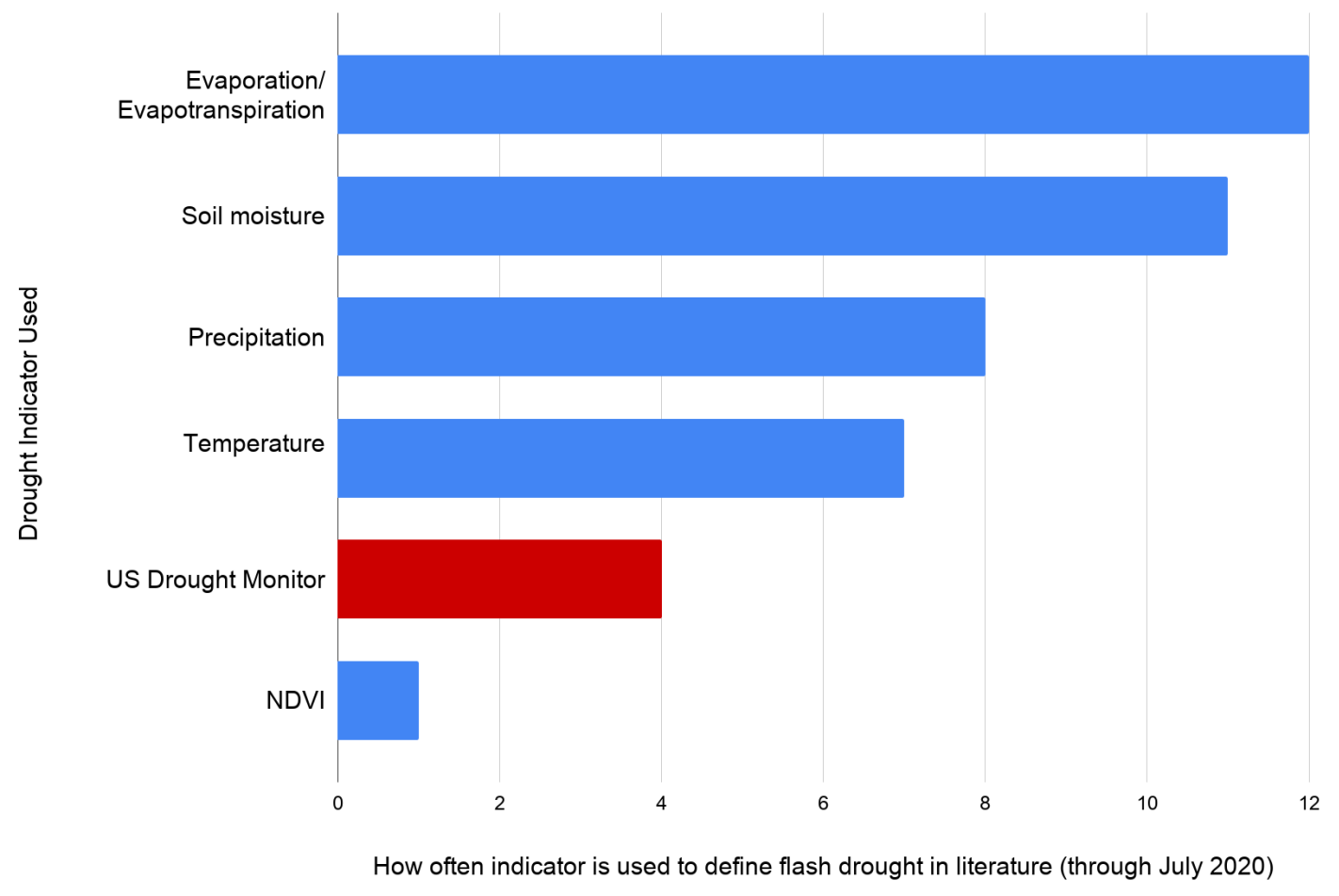

FIGURE 2: How often a climate indicator was used in a flash drought definition. The base elements from composite indices were counted separately. For example, the Standardized Precipitation Evaporation Index (SPEI) was used in one definition, but here evaporation and precipitation were counted as separate indicators that were combined for that definition. The US Drought Monitor is highlighted (red) because this represents a synthesis of indicators (as opposed to a single indicator) and is, therefore, different from the others on this chart. 
et al. 2018; Kimball et al. 2019; and He et al. 2019). While not an exhaustive list, these papers demonstrate that flash drought can be looked at in a myriad of ways, using various indicators within the climate system, without necessarily setting terms or thresholds to diagnose a flash drought event (Zhang et al. 2020).

When considering the indicators used to define flash drought, we also considered the studies that used multiple indicators to define the phenomena (see Appendix 5 and Figure 3). Of the 20 papers cited here that defined flash drought using a set of criteria, One included four indicators, five used a combination of three indicators, five used a combination of two indicators and the remaining nine papers used a single indicator (counting the SPEI as a single indicator in this case). Of the total 20 papers, three used the US Drought Monitor, which represents a synthesis of indicators.

\section{Summary and Conclusions}

Given how active the flash drought research field has become, we were motivated to conduct this literature review as a way to synthesize the current research, highlight some of the questions and incongruities that exist within the literature, and provide a basis for future research on flash drought.

Since flash drought first appeared in the scientific literature in 2002 there have been 29 general descriptions and 20 papers providing defining criteria across 86 papers and 325 authors/co-authors (as of July 2020). We reviewed these definitions and grouped them by papers that provide only a general description (29 papers), papers that define flash drought by the rate of onset or intensification (11 papers), papers that consider flash droughts to be short-term drought events ( 8 papers), and one paper that considers both rate of onset and short-term duration. We have made these definitions available so that they can be utilized in future research.

While we have not assessed the merits or demerits of any individual criteria or method, we have noted the variety of ways that flash drought has been measured. For example, definitions that consider flash drought as a rapid-onset event include a range of onset rates from five days to eight weeks. Four papers used changes in the US Drought Monitor to define flash drought. The most common indicators of flash drought have been evaporation/evapotranspiration (12 times), soil moisture (used 11 times), precipitation (8 times) and temperature ( 7 times). It is clear from reviewing these papers that flash drought can be identified using a variety of indices. Despite a call in 2018 for flash drought definitions to be based on the principle of rapid-intensification (Otkin et al. 2018a), new definitions calling short-duration events a "flash drought" continue to be published. Thus, within the current understanding, the term "flash drought" could be used to mean either a drought that formed or intensified rapidly, or a drought that was intense (usually associated with a heatwave) but relatively short-lived.

Upon completing this review it is clear that there are many differences among the way the term "flash drought" has

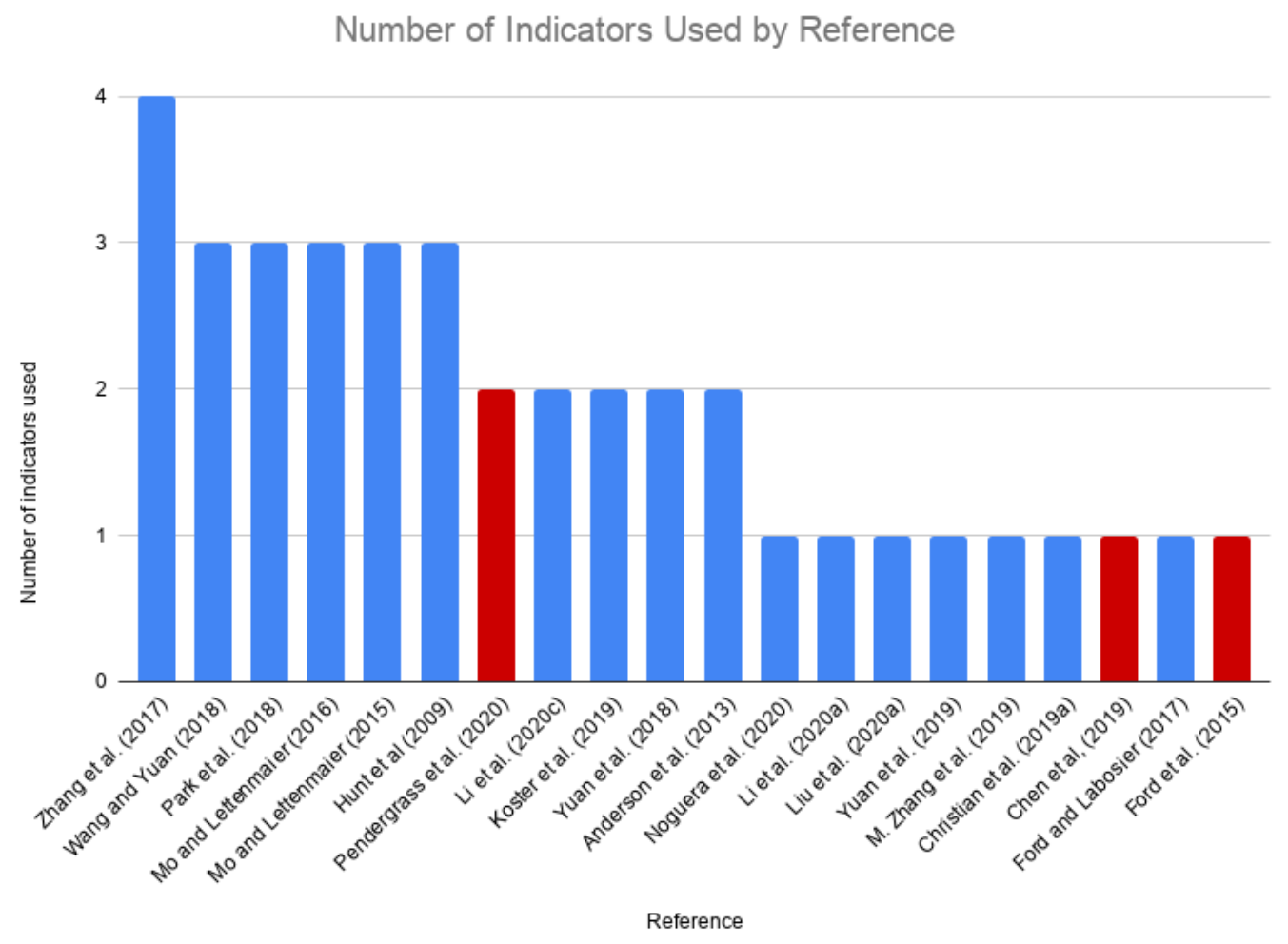

FIGURE 3: Number of indicators used in each flash drought definition. Red bars indicate if that definition used the US Drought Monitor, which represents a synthesis of indicators. 
been used in the literature, but there are also some common themes. The first commonality being that a flash drought represents a rapid change in the available water in the landscape, whether those changes persist or not or whether those changes occur at the beginning of the drought (rapid onset) or at some point throughout the event (rapid intensification). Another theme that was sometimes explicitly stated (e.g. Anderson et al. 2015; Cook et al. 2018; Zheng et al. 2019) and other times implied (e.g. Otkin et al. 2015a; Mo and Lettenmaier 2016) is that flash drought often hits without (or with very little) warning and is often not picked up in seasonal climate forecast (e.g. PaiMazumder and Done 2016; Pendergrass et al. 2020) or by the US Drought monitor (e.g. Basara et al. 2019; Jin et al. 2019). In other words, the research commonly notes that flash drought can have dire impacts with little-to-no warning.

Given that flash drought has real relevance and implications for a wide range of resource managers, we call on flash drought researchers to be mindful that as they work to define this phenomenon they should think beyond their particular research interests to the broader societal relevance. Given the impact of flash drought on various sectors of society, this is not just a technical physical science issue.

We are not sure it is necessary (or possible) to limit flash drought to a single rigid definition with an immutable set of criteria because the methodology used should be appropriate for the question asked. However, a clear set of guidelines to distinguish flash drought events from other droughts should be agreed upon. It is the opinion of the authors that when the term "flash drought" is used, its intended meaning should be stated explicitly. We further encourage researchers to explicitly engage in discussion of how to characterize and define flash drought, both within the literature and at workshops and conferences, such as the one held by NOAA's National Integrated Drought Information System (NIDIS) in late 2020. We expect this discourse will continue within future publications, and we call on the ever-growing flash drought research community to consider methodologies and definitions that are robust, reproducible, and useful to those impacted by future flash drought events.

\section{Acknowledgements}

The authors would like to convey our thanks to the two anonymous reviewers of the draft paper; their comments really helped us to sharpen our manuscript. We further acknowledge the direction given to early concepts of this paper by Andy Hoell, Jason Otkin, Mark Svoboda, Mike Hobbins, Trent Ford and Veva Deheza.

\section{REFERENCES}

AghaKouchak, A., 2014: A baseline probabilistic drought forecasting framework using standardized soil moisture index: Application to the 2012 United States drought. Hydrol. Earth Syst. Sci., 18, 2485-2492, https://doi. org/10.5194/hess-18-2485-2014.

Anderson, M. C., C. Hain, B. Wardlow, A. Pimstein, J. R. Mecikalski, and W. P. Kustas, 2011: Evaluation of Drought Indices Based on Thermal Remote Sensing of Evapotranspiration over the Continental United States. J. Clim., 24, 2025-2044, https://doi.org/10.1175/2010JCLI3812.1.

- - J. Otkin, X. Zhan, K. Mo, M. Svoboda, B. Wardlow, and A. Pimstein, 2013: An Intercomparison of Drought Indicators Based on Thermal Remote Sensing and NLDAS-2 Simulations with U.S. Drought Monitor Classifications. J. Hydrometeor., 14, 1035-1056, https:// doi.org/10.1175/JHM-D-12-0140.1.

_, C. A. Zolin, C. R. Hain, K. Semmens, M. Tugrul Yilmaz, and F. Gao, 2016: Comparison of satellite-derived LAI and precipitation anomalies over Brazil with a thermal infrared-based Evaporative Stress Index for 20032013. J. Hydrol., 526, 287-302, https://doi.org/10.1016/j. jhydrol.2015.01.005.

Basara, J. B., J. I. Christian, R. A. Wakefield, J. A. Otkin, E. H. Hunt, and D. P. Brown, 2019: The evolution, propagation, and spread of flash drought in the Central United States during 2012. Environ. Res. Lett., 14, https://doi. org/10.1088/1748-9326/ab2cc0.

Behrangi, A., P. C. Loikith, E. J. Fetzer, H. M. Nguyen, and S. L. Granger, 2015: Utilizing humidity and temperature data to advance monitoring and prediction of meteorological drought. Climate, 3, 999-1017, https://doi. org/10.3390/cli3040999.

Bollasina, M. A., and G. Messori, 2018: On the link between the subseasonal evolution of the North Atlantic Oscillation and East Asian climate. Clim. Dyn., 51, 3537-3557, https://doi.org/10.1007/s00382-018-4095-5.

Brown, J. R., D. Kluck, C. McNutt, and M. Hayes, 2016: Assessing Drought Vulnerability Using a Socioecological Framework. Rangelands, 38, 162-168, https://doi. org/10.1016/j.rala.2016.06.007.

Cammalleri, C., F. Micale, and J. Vogt, 2016: A novel soil moisture-based drought severity index (DSI) combining water deficit magnitude and frequency. Hydrol. Process., 30, 289-301, https://doi.org/10.1002/hyp.10578.

Chen, L. G., J. Gottschalck, A. Hartman, D. Miskus, R. Tinker, and A. Artusa, 2019: Flash drought characteristics based on U.S. drought monitor. Atmosphere (Basel)., 10, https://doi.org/10.3390/atmos10090498.

Christian, J. I., J. B. Basara, J. A. Otkin, E. D. Hunt, R. A. Wakefield, P. X. Flanagan, and X. Xiao, 2019a: A Methodology for Flash Drought Identification: Application of Flash Drought Frequency across the United States. J. Hydrometeor., 20, 833-846, https://doi.org/10.1175/ 


\section{JHM-D-18-0198.1.}

Christian, J. I., J. B. Basara, J. A. Otkin, and E. D. Hunt, 2019b Regional characteristics of flash droughts across the United States. Environ. Res. Commun., 1, 125004, https://doi.org/10.1088/2515-7620/ab50ca.

Cook, B. I., J. S. Mankin, and K. J. Anchukaitis, 2018: Climate Change and Drought: From Past to Future. Curr. Clim. Chang. Reports, 4, 164-179, https://doi. org/10.1007/s40641-018-0093-2.

Ford, T. W., and C. F. Labosier, 2017: Meteorological conditions associated with the onset of flash drought in the Eastern United States. Agric. For. Meteor., 247, 414-423, https://doi.org/10.1016/j.agrformet.2017.08.031.

, D. B. McRoberts, S. M. Quiring, and R. E. Hall, 2015: On the utility of in situ soil moisture observations for flash drought early warning in Oklahoma, USA. Geophys. Res. Lett., 42, 9790-9798, https://doi. org/10.1002/2015GL066600.

Fowler, H. J., and C. G. Kilsby, 2002: A weather-type approach to analyzing water resource drought in the Yorkshire region from 1881 to 1998. J. Hydrol., 262, 177-192, https://doi.org/10.1016/S0022-1694(02)00034-3.

Gerken, T., G. T. Bromley, B. L. Ruddell, S. Williams, and P. C. Stoy, 2018: Convective suppression before and during the United States Northern Great Plains flash drought of 2017. Hydrol. Earth Syst. Sci., 22, 4155-4163, https:// doi.org/10.5194/hess-22-4155-2018.

Haigh, T. R., J. A. Otkin, A. Mucia, M. Hayes, and M. E. Burbach, 2019: Drought Early Warning and the Timing of Range Managers' Drought Response. Adv. Meteor., 2019, https://doi.org/10.1155/2019/9461513.

Haile, G. G., Q. Tang, W. Li, X. Liu, and X. Zhang, 2020: Drought: Progress in broadening its understanding. WIREs Water, 7, 1-25, https://doi.org/10.1002/ wat2.1407.

Han, Z., and Coauthors, 2019: Propagation dynamics from meteorological to groundwater drought and their possible influence factors. J. Hydrol., 578, 124102, https://doi. org/10.1016/j.jhydrol.2019.124102.

Hao, Z., Y. Xia, L. Luo, V. P. Singh, W. Ouyang, and F. Hao, 2017: Toward a categorical drought prediction system based on U.S. Drought Monitor (USDM) and climate forecast. J. Hydrol., 551, 300-305, https://doi. org/10.1016/j.jhydrol.2017.06.005.

He, M., J. S. Kimball, Y. Yi, S. Running, K. Guan, K. Jensco, B. Maxwell, and M. Maneta, 2019: Impacts of the 2017 flash drought in the US Northern plains informed by satellite-based evapotranspiration and solar-induced fluorescence. Environ. Res. Lett., 14, https://doi. org/10.1088/1748-9326/ab22c3.

Heim, R. R., C. Guard, M. A. Lander, and B. Bukunt, 2020:
USAPI USDM: Operational drought monitoring in the U.S.-affiliated pacific islands. Atmosphere (Basel)., 11, 1-9, https://doi.org/10.3390/ATMOS11050495.

Hobbins, M., D. McEvoy, and C. Hain, 2017: Evapotranspiration, Evaporative Demand, and Drought. 259-288 pp.

Hobbins, M. T., A. Wood, D. J. McEvoy, J. L. Huntington, C. Morton, M. Anderson, and C. Hain, 2016: The evaporative demand drought index. Part I: Linking drought evolution to variations in evaporative demand. J. Hydrometeor., 17, 1745-1761, https://doi.org/10.1175/ JHM-D-15-0121.1.

Hoell, A., J. Perlwitz, and J. Eischeid, 2019: The Causes, Predictability, and Historical Context of the 2017 U.S. Northern Great Plains Drought. 25 pp. https://repository.library.noaa.gov/view/noaa/23003/noaa_23003_DS1. pdf.

Hoerling, M., S. Schubert, and K. C. Mo, 2013: An Interpretation of the Origins of the 2012 Central Great Plains Drought Assessment Report. 50 pp.

— J. Jischeid, A. Kumar, R. Leung, A. Mariotti, K. Mo, S. Schubert, and R. Seager, 2014: Causes and Predictability of the 2012 Great Plains Drought. Bull. Amer. Meteor. Soc., 95, 269-282, https://doi.org/10.1175/ BAMS-D-13-00055.1.

Hunt, E. D., K. G. Hubbard, D. A. Wilhite, T. J. Arkebauer, and A. L. Dutcher, 2009: The development and evaluation of a soil moisture index. Int. J. Climatol., 29, 747759, https://doi.org/10.1002/joc. 1749.

- M. Svoboda, B. Wardlow, K. Hubbard, M. Hayes, and T. Arkebauer, 2014: Monitoring the effects of rapid onset of drought on non-irrigated maize with agronomic data and climate-based drought indices. Agric. For. Meteor., 191, 1-11, https://doi.org/10.1016/j.agrformet.2014.02.001.

Illston, B. G., J. B. Basara, and K. C. Crawford, 2004: Seasonal to interannual variations of soil moisture measured in Oklahoma. Int. J. Climatol., 24, 1883-1896, https:// doi.org/10.1002/joc.1077.

Jin, C., X. Luo, X. Xiao, J. Dong, X. Li, J. Yang, and D. Zhao, 2019: The 2012 Flash Drought Threatened US Midwest Agroecosystems. Chinese Geogr. Sci., 29, 768 783, https://doi.org/10.1007/s11769-019-1066-7.

Kim, D., W. S. Lee, S. T. Kim, and J. A. Chun, 2019: Historical Drought Assessment Over the Contiguous United States Using the Generalized Complementary Principle of Evapotranspiration. Water Resour. Res., 55, 62446267, https://doi.org/10.1029/2019WR024991.

Kimball, J. S., L. Jones, K. Jensco, M. He, M. Maneta, and R. Reichle, 2019: SMAP L4 Assessment of the US Northern Plains 2017 Flash Drought. International Geoscience and Remote Sensing Symposium (IGARSS), 5366-5369. 
Koster, R. D., S. D. Schubert, H. Wang, S. P. Mahanama, and A. M. Deangelis, 2019: Flash drought as captured by reanalysis data: Disentangling the contributions of precipitation deficit and excess evapotranspiration. J. Hydrometeor., 20, 1241-1258, https://doi.org/10.1175/ JHM-D-18-0242.1.

Krueger, E. S., T. E. Ochsner, D. M. Engle, J. D. Carlson, D. Twidwell, and S. D. Fuhlendorf, 2015: Soil Moisture Affects Growing-Season Wildfire Size in the Southern Great Plains. Soil Sci. Soc. Am. J., 79, 1567-1576, https://doi. org/10.2136/sssaj2015.01.0041.

Kumar, A., M. Chen, M. Hoerling, and J. Eischeid, 2013: Do extreme climate events require extreme forcings? Geophys. Res. Lett., 40, 3440-3445, https://doi.org/10.1002/ grl.50657.

Lee, J. A., and T. E. Gill, 2015: Multiple causes of wind erosion in the Dust Bowl. Aeolian Res., 19, 15-36, https:// doi.org/10.1016/j.aeolia.2015.09.002.

Li, J., Z. Wang, X. Wu, J. Chen, S. Guo, and Z. Zhang, 2020a: A new framework for tracking flash drought events in space and time. Catena, 194, 104763, https:// doi.org/10.1016/j.catena.2020.104763.

$-\longrightarrow,-$, S. Guo, and X. Chen, 2020b: Flash droughts in the Pearl River Basin, China: Observed characteristics and future changes. Sci. Total Environ., 707, 136074, https://doi.org/10.1016/j.scitotenv.2019.136074.

,,--- C. Y. Xu, S. Guo, and X. Chen, 2020c: Toward monitoring short-term droughts using a novel daily scale, standardized antecedent precipitation evapotranspiration index. J. Hydrometeor., 21, 891-908, https://doi.org/10.1175/JHM-D-19-0298.1.

Liu, Y., Y. Zhu, L. Ren, J. Otkin, E. D. Hunt, X. Yang, F. Yuan, and S. Jian, 2020a: Two different methods for flash drought identification: Comparison of their strengths and limitations. J. Hydrometeor., 21, 691-704, https://doi. org/10.1175/JHM-D-19-0088.1.

,-- L. Zhang, L. Ren, F. Yuan, X. Yang, and S. Jiang, 2020b: Flash droughts characterization over China: From a perspective of the rapid intensification rate. Sci. Total Environ., 704, 135373, https://doi.org/10.1016/j. scitotenv.2019.135373.

Lorenz, D. J., J. A. Otkin, M. Svoboda, C. R. Hain, M. C. Anderson, and Y. Zhong, 2017a: Predicting U.S. Drought Monitor States Using Precipitation, Soil Moisture, and Evapotranspiration Anomalies. Part I: Development of a Nondiscrete USDM Index. J. Hydrometeor., 18, 19431962, https://doi.org/10.1175/JHM-D-16-0066.1.

, and,$- 2017 \mathrm{~b}$ : Predicting the U.S. drought monitor using precipitation, soil moisture, and evapotranspiration anomalies. Part II: Intraseasonal drought intensification forecasts. J. Hydrometeor., 18, 1963-1982, https://doi.org/10.1175/
JHM-D-16-0067.1.

Lorenz, D. J., J. A. Otkin, M. Svoboda, C. R. Hain, and Y. Zhong, 2018: Forecasting Rapid Drought Intensification Using the Climate Forecast System (CFS). J. Geophys. Res. Atmos., 123, 8365-8373, https://doi.org/10.1029/ 2018JD028880.

McEvoy, D. J., J. L. Huntington, M. T. Hobbins, A. Wood, C. Morton, M. Anderson, and C. Hain, 2016: The evaporative demand drought index. Part II: CONUS-wide assessment against common drought indicators. J. Hydrometeor., 17, 1763-1779, https://doi.org/10.1175/ JHM-D-15-0122.1.

McNider, R. T., and Coauthors, 2015: An integrated crop and hydrologic modeling system to estimate hydrologic impacts of crop irrigation demands. Environ. Model. Softw., 72, 341-355, https://doi.org/10.1016/j.envsoft.2014.10.009.

Mo, K. C., and D. P. Lettenmaier, 2015: Heat wave flash droughts in decline. Geophys. Res. Lett., 42, 2823-2829, https://doi.org/10.1002/2015GL064018.

Mo, K. C., and D. P. Lettenmaier, 2016: Precipitation deficit flash droughts over the United States. J. Hydrometeor., 17, 1169-1184, https://doi.org/10.1175/JHM-D-15-0158.1.

Mozny, M., M. Trnka, Z. Zalud, P. Hlavinka, J. Nekovar, V. Potop, and M. Virag, 2012: Use of a soil moisture network for drought monitoring in the Czech Republic. Theor. Appl. Climatol., 107, 99-111, https://doi.org/10.1007/ s00704-011-0460-6.

Nguyen, H., M. C. Wheeler, J. A. Otkin, T. Cowan, A. Frost, and R. Stone, 2019: Using the evaporative stress index to monitor flash drought in Australia. Environ. Res. Lett., 14, https://doi.org/10.1088/1748-9326/ab2103.

Noguera, I., F. Domínguez-Castro, and S. M. Vicente-Serrano, 2020: Characteristics and trends of flash droughts in Spain, 1961-2018. Ann. N. Y. Acad. Sci., 1472, 155-172, https://doi.org/10.1111/nyas.14365.

Obringer, R., X. Zhang, K. Mallick, S. H. Alemohammad, and D. Niyogi, 2016: Assessing urban droughts in a smart city framework. Int. Arch. Photogramm. Remote Sens. Spat. Inf. Sci. - ISPRS Arch., 41, 747-751, https://doi. org/10.5194/isprsarchives-XLI-B2-747-2016.

Otkin, J. A., M. C. Anderson, C. Hain, I. E. Mladenova, J. B. Basara, and M. Svoboda, 2013: Examining rapid onset drought development using the thermal infrared-based evaporative stress index. J. Hydrometeor., 14, 10571074, https://doi.org/10.1175/JHM-D-12-0144.1.

$-, \ldots,-$, and M. Svoboda, 2014: Examining the Relationship between Drought Development and Rapid Changes in the Evaporative Stress Index. J. Hydrometeor., 15, 938-956, https://doi.org/10.1175/JHM-D-13-0110.1. and —-, 2015a: Using temporal chang- 
es in drought indices to generate probabilistic drought intensification forecasts. J. Hydrometeor., 16, 88-105, https://doi.org/10.1175/JHM-D-14-0064.1.

—, M. Shafer, M. Svoboda, B. Wardlow, M. C. Anderson, C. Hain, and J. Basara, 2015b: Facilitating the use of drought early warning information through interactions with agricultural stakeholders. Bull. Amer. Meteor. Soc., 96, 1073-1078, https://doi.org/10.1175/ BAMS-D-14-00219.1.

Otkin, J. A., and Coauthors, 2016: Assessing the evolution of soil moisture and vegetation conditions during the 2012 United States flash drought. Agric. For. Meteor., 218-219, 230-242, https://doi.org/10.1016/j.agrformet.2015.12.065.

—, M. Svoboda, E. D. Hunt, T. W. Ford, M. C. Anderson, C. Hain, and J. B. Basara, 2018a: Flash Droughts: A Review and Assessment of the Challenges Imposed by Rapid-Onset Droughts in the United States. Bull. Amer. Meteor. Soc., 99, 911-919, https://doi.org/10.1175/ BAMS-D-17-0149.1.

- T. Haigh, A. Mucia, M. C. Anderson, and C. Hain, 2018b: Comparison of Agricultural Stakeholder Survey Results and Drought Monitoring Datasets during the 2016 U.S. Northern Plains Flash Drought. Wea. Clim. Soc., 10, 867-883, https://doi.org/10.1175/wcas-d-18-0051.1.

—, Y. Zhong, E. D. Hunt, J. Basara, M. Svoboda, M. C. Anderson, and C. Hain, 2019: Assessing the evolution of soil moisture and vegetation conditions during a flash drought-flash recovery sequence over the South-Central United States. J. Hydrometeor., 20, 549-562, https://doi. org/10.1175/JHM-D-18-0171.1.

PaiMazumder, D., and J. M. Done, 2016: Potential predictability sources of the 2012 U.S. drought in observations and a regional model ensemble. J. Geophys. Res., 121, 12,581-12,592, https://doi.org/10.1002/2016JD025322.

Palmer, W. C., 1965: Meteorological Drought. U.S. Wea. Bur. Res. Pap. No. 45, 58.

Park, S., E. Seo, D. Kang, J. Im, and M. I. Lee, 2018: Prediction of drought on pentad scale using remote sensing data and MJO index through random forest over East Asia. Remote Sens., 10, 1-18, https://doi.org/10.3390/ rs10111811.

Pendergrass, A. G., and Coauthors, 2020: Flash droughts present a new challenge for subseasonal-to-seasonal prediction. Nat. Clim. Chang., 10, 191-199, https://doi. org/10.1038/s41558-020-0709-0.

Peters, A. J., E. Walter-shea, A. Vina, M. Hayes, and M. D. Svoboda, 2002: Drought monitoring with NDVI-based Standardized Vegetation Index. Photogramm. Eng. Remote Sens., 68, 71-75.

Pickering, C., and J. Byrne, 2014: The benefits of publishing systematic quantitative literature reviews for $\mathrm{PhD}$ candidates and other early-career researchers. High. Educ. Res. Dev., 33, 534-548, https://doi.org/10.1080/07294360.20 13.841651 .

Potop, V., C. Boroneanţ, M. Možný, P. Štěpánek, and P. Skalák, 2014: Observed spatiotemporal characteristics of drought on various time scales over the Czech Republic. Theor. Appl. Climatol., 115, 563-581, https://doi. org/10.1007/s00704-013-0908-y.

Ran, H., J. Li, Z. Zhou, C. Zhang, C. Tang, and Y. Yu, 2020: Predicting the spatiotemporal characteristics of flash droughts with downscaled CMIP5 models in the Jinghe River basin of China. Environ. Sci. Pollut. Res., https:// doi.org/10.1007/s11356-020-10036-3.

Rupp, D. E., S. Li, P. W. Mote, N. Massey, S. N. Sparrow, and D. C. H. Wallom, 2017: Influence of the Ocean and Greenhouse Gases on Severe Drought Likelihood in the Central United States in 2012. J. Clim., 30, 1789-1806, https://doi.org/10.1175/JCLI-D-16-0294.1.

Sánchez, N., Á. González-Zamora, M. Piles, and J. Martínez-Fernández, 2016: A new Soil Moisture Agricultural Drought Index (SMADI) integrating MODIS and SMOS products: A case of study over the Iberian Peninsula. Remote Sens., 8, https://doi.org/10.3390/rs8040287.

Senay, G. B., M. E. Budde, J. F. Brown, and J. P. Verdin, 2008: Mapping Flash Drought in the U.S. Southern Great Plains. AMS, 22nd Conference on Hydrology, Session 6, Drought Assessment and Prediction, Part II, New Orleans, LA, American Meteorological Society https://ams. confex.com/ams/88Annual/techprogram/paper_134349. htm.

Showstack, R., 1999: U. S. Federal Government Tries to Get Ahead of the Curve with Drought Planning. EOS, transactions American Geophysical Union, August.

Stojanovic, M., and Coauthors, 2020: Trends and Extremes of Drought Episodes in Vietnam Sub-Regions during 1980-2017 at Different Timescales. Water, 12, 813, https://doi.org/10.3390/w12030813.

Sun, D., Y. Li, X. Zhan, P. Houser, C. Yang, L. Chiu, and R. Yang, 2019: Land surface temperature derivation under all sky conditions through integrating AMSR-E/AMSR2 and MODIS/GOES observations. Remote Sens., 11, 1-20, https://doi.org/10.3390/rs11141704.

Sun, Y., R. Fu, R. Dickinson, J. Joiner, C. Frankenberg, L. Gu, Y. Xia, and N. Fernando, 2015: Drought onset mechanisms revealed by satellite solar-induced chlorophyll fluorescence: Insights from two contrasting extreme events. J. Geophys. Res. G Biogeosciences, 120, $2427-$ 2440, https://doi.org/10.1002/2015JG003150.

Svoboda, M., and Coauthors, 2002: The Drought Monitor. Bull. Amer. Meteor. Soc., 83, 1181-1190, https://doi. org/10.1175/1520-0477-83.8.1181. 
Trenberth, K. E., G. W. Branstator, and P. A. Arkin, 1988: Origins of the 1988 North American Drought. Science (80-. )., 242, 1640-1645, https://doi.org/10.1126/science.242.4886.1640.

Trnka, M., and Coauthors, 2020: Czech Drought Monitor System for monitoring and forecasting agricultural drought and drought impacts. Int. J. Climatol., 40, 59415958, https://doi.org/10.1002/joc.6557.

Twidwell, D., C. L. Wonkka, C. A. Taylor, C. B. Zou, J. J. Twidwell, and W. E. Rogers, 2014: Drought-induced woody plant mortality in an encroached semi-arid savanna depends on topoedaphic factors and land management. Appl. Veg. Sci., 17, 42-52, https://doi.org/10.1111/ avsc. 12044.

Vogt, J. V., and Coauthors, 2018: Drought Risk Assessment and Management. A conceptual framework. 68 pp.

Wang, L., and X. Yuan, 2018: Two Types of Flash Drought and Their Connections with Seasonal Drought. Adv. Atmos. Sci., 35, 1478-1490, https://doi.org/10.1007/ s00376-018-8047-0.

,-- Z. Xie, P. Wu, and Y. Li, 2016: Increasing flash droughts over China during the recent global warming hiatus. Nat. Publ. Gr., 1-8, https://doi.org/10.1038/ srep30571.

Wang, S. -Y. S., and Coauthors, 2015: An intensified seasonal transition in the Central U.S. that enhances summer drought. J. Geophys. Res. Atmos., 120, 8804-8816, https://doi.org/10.1002/2014JD023013.

Yan, H., M. Zarekarizi, and H. Moradkhani, 2018: Toward improving drought monitoring using the remotely sensed soil moisture assimilation: A parallel particle filtering framework. Remote Sens. Environ., 216, 456-471, https://doi.org/10.1016/j.rse.2018.07.017.

Yang, Y., and Coauthors, 2018: Field-scale mapping of evaporative stress indicators of crop yield: An application over Mead, NE, USA. Remote Sens. Environ., 210, 387-402, https://doi.org/10.1016/j.rse.2018.02.020.

Yao, N., Y. Li, T. Lei, and L. Peng, 2018: Drought evolution, severity and trends in mainland China over 19612013. Sci. Total Environ., 616-617, 73-89, https://doi. org/10.1016/j.scitotenv.2017.10.327.

Yuan, X., Z. Ma, M. Pan, and C. Shi, 2015: Microwave remote sensing of short-term droughts during crop growing seasons. Geophys. Res. Lett., 42, 4394-4401, https://doi. org/10.1002/2015GL064125.

, L. Wang, and E. Wood, 2018: Anthropogenic Intensification of Southern African Flash Droughts As Exemplified By The 2015/16 Season [in "Explaining Extreme Events of 2016 from a Climate Perspective"]. Bull. Amer. Meteor. Soc., 99 (1), S54-S59, https://doi.org/10.1175/ BAMS-D-17-0077.1.
- - - P. Wu, P. Ji, J. Sheffield, and M. Zhang, 2019: Anthropogenic shift towards higher risk of flash drought over China. Nat. Commun., 10, 4661, https://doi. org/10.1038/s41467-019-12692-7.

Zhang, H., C. Wu, and B. X. Hu, 2019: Recent intensification of short-term concurrent hot and dry extremes over the Pearl River basin, China. Int. J. Climatol., 39, 49244937, https://doi.org/10.1002/joc.6116.

Zhang, M., S. Chen, H. Jiang, Y. Lin, J. Zhang, X. Song, and G. Zhou, 2019: Water-Use Characteristics and Physiological Response of Moso Bamboo to Flash Droughts. Int. J. Environ. Res. Public Health, 16, 2174, https://doi. org/10.3390/ijerph16122174.

Zhang, Q., and Coauthors, 2020: Causes and Changes of Drought in China: Research Progress and Prospects. J. Meteor. Res., 34, 460-481, https://doi.org/10.1007/ s13351-020-9829-8.

Zhang, Y., Q. You, C. Chen, and X. Li, 2017: Flash droughts in a typical humid and subtropical basin: A case study in the Gan River Basin, China. J. Hydrol., 551, 162-176, https://doi.org/10.1016/j.jhydrol.2017.05.044.

,,--- J. Ge, and M. Adnan, 2018: Evaluation of Downscaled CMIP5 Coupled with VIC Model for Flash Drought Simulation in a Humid Subtropical Basin, China. J. Clim., 31, 1075-1090, https://doi.org/10.1175/ JCLI-D-17-0378.1.

Zheng, L., Y. Zhu, and R. Jiang, 2019: The Mediating Role of Moral Elevation in Cause-Related Marketing: A Moral Psychological Perspective. J. Bus. Ethics, 156, 439-454, https://doi.org/10.1007/s10551-017-3614-3. 


\section{APPENDICES}

\section{APPENDIX 1. List of generalized flash drought descriptions in chronological order.}

Reference Generic Descriptions

Peters et al. $\quad$ "flash drought...combination of no precipitation and very high temperatures..." (p. 73)

(2002) Referenced by Lee and Gill (2015); Twidwell et al. (2014)

Svoboda et "flash drought...refers to rapid crop deterioration due to the adverse effects of a severe heat wave and al. (2002) short-term dryness, leading to a rapid onset of drought and associated impacts in agriculture, fire potential, livestock health, and other areas." (p. 1184)

Referenced by Hunt et al. (2014); Otkin et al. (2014); McEvoy et al. (2016); Cammalleri et al. (2016); Lorenz et al. (2017a); Cook et al. (2018); Bollasina and Messori (2018); Otkin et al. (2018a); Jin et al. (2019); Heim et al. (2020); Noguera et al. (2020)

Senay et al. "A flash drought is considered to be a short-term, yet severe event, characterized by moisture deficits and (2008) abnormally high temperatures." (Abstract)

Referenced by Hunt et al. (2009); Mozny et al. (2012) [Mozny et al. (2012) is then referenced by Otkin et al. (2013)]; Potop et al. (2014); Krueger et al. (2015); Sanchez et al. (2016)

Anderson et "...the so-called flash drought events, where prolonged hot, dry, and windy conditions lead to rapid water al. (2011) loss and the potential for catastrophic crop yield loss." (p. 2041)

Hunt et al. "Short-term drought, sometimes referred to as flash drought, is a rapid onset of drought often accompa(2014) nied by high temperatures and winds that lead to rapid soil moisture depletion during a critical time in the growing season (Svoboda et al. 2002).” (p. 2)

Otkin et al. "...the term 'flash drought' has been used to better distinguish rapid-onset drought events from those that (2014) develop more slowly (e.g., Otkin et al. 2013; Svoboda et al. 2002). This Terminology captures the distinguishing characteristic of these droughts, namely, their unusually rapid rate of intensification." (p. 939)

Sun et al. "...the 2012 drought in the central Great Plains was preceded by relatively normal precipitation and warm(2015) er surface temperature in spring followed by an abrupt rainfall reduction and abnormally high temperatures in summer, typifying a "flash" drought (Hoerling et al. 2014; Mo and Lettenmaier, 2015)." (p. 2430)

Yuan et al. Drought (general) "is defined as the monthly soil moisture percentile is lower than $20 \%$ or the SPI-1 is less (2015) than 0.8 [Svoboda et al. 2002]." (p. 4396)

Flash drought is considered a "short-term (monthly to seasonal) drought" (p. 4394)

Anderson et "rapid onset - or 'flash' - drought events" (p. 83)

al. (2016)

Brown et al. "rapid onset droughts known as 'flash drought'...evolve in a matter of weeks and are usually characterized (2016) by a relatively short period of low rainfall combined with an extended period of anomalously high temperatures." (p. 166)

Cammalleri "rapidly occurring events of dryness that last less than 1 year" (p. 289)

et al. (2016)

Hobbins et “' 'Flash Drought'...i.e., fast-developing drought driven by strong, transient meteorological/radiative al. (2016) changes - such as increases in $T_{\text {air }}$, wind, or radiation, or decreases in humidity - with no substantive change in Prcp." (p. 1747)

Obringer et A flash drought is a drought that occurs over a small temporal scale, often for the length of a season." (p. al. (2016) 750)

Sanchez et "flash drought, defined as a severe, short-term event characterized by soil moisture al. (2016) deficit and abnormally high temperatures, thus negatively impacting vegetation conditions." (p. 1)

Hobbins et "flash (or rapid onset) drought" (p. 265) al. (2017)

Cook et al. "This term [Flash drought] is typically used to refer to soil moisture droughts that develop and intensify (2018) rapidly (especially over the summer), with often little or no advance warning." (p. 170)

Yao et al. Generally: flash drought is a rapid-onset drought event (2018) 


\section{APPENDIX 1 CONTINUED}

Otkin et al. Flash Drought: "a subset of all droughts that are distinguished from more conventional slowly developing (2018a) droughts by their unusually rapid rate of intensification." (p. 914)

Referenced by Otkin et al. 2018b, 2019; Basara et al. 2019; Nguyen et al. 2019; He et al. 2019; Haigh et al. 2019; Christian et al. 2019a, b)

Lorenz et al. Generally: if the US Drought Monitor is more intense in 2, 4, or 6 weeks then the authors considered this (2018) a rapid onset to the drought situation.

Gerken et al. Described "rapid onset" droughts, and in the case study used the Northern Great Plains 2017 drought (2018) which set in over 2-to-4 months depending on the location.

Vogt et al. Describes flash drought as one that lasts less than 3 months (2018)

Hoell et al. Described the 2017 Northern Great Plains drought as a "rapid" decrease in soil moisture, leading to agri(2019) cultural drought that ended only three months after it began.

Jin et al. "short-term drought events with a rapid on-set and intensification rate (Svoboda et al. 2002).” (p. 769) (2019)

Han et al. "The concurrent drought and heatwave events with low soil moisture...and high ET are recently termed as (2019) 'flash drought' (Yuan et al. 2015)." (p. 7)

Zheng et al. "Flash drought refers to relatively short periods of warm surface temperature and anomalously low (2019) and rapid decreasing soil moisture (Mo and Lettenmaier 2016). Compared with traditional slow-onset and long-term droughts, flash droughts are unexpected and bring a grand challenge for early warning due to limited prior external signals, as well as lead to devastating impacts on crop yields and water supply

(Wang et al. 2016)." (p. 441)

Haile et al. "Flash droughts are short term, rapidly evolving drought events during crop growing seasons, occurring (2020) S S Simultaneously with unusually high temperature (Yuan, Ma, Pan, \& Shi, 2015)." (p. 8)

H. Zhang et "Flash drought is a short-term drought event that develops rapidly in association with a high-temperature al. (2020) heat wave. It occurs suddenly with fast development and high intensity, posing a serious threat to crop yield and water supply." (p. 470)

Stojanovic Flash droughts: "episodes with sudden onset and a short duration, e.g., 1 or 2 months" (p. 12)

et al. (2020)

Trnka et al. "flash drought events, that is, sharp intensification of lower intensity droughts occurring in the space of (2020) days or weeks" (p. 5942)

APPENDIX 2. List of flash drought definitions based on the rate of onset, in chronological order.

Reference Onset rate criteria

Anderson et Flash drought was not explicitly defined, but the authors looked for periods when changes in Evaporative al. (2013) Stress Index (ESI) and Soil Moisture (SM) occurring over a 4-week interval were strong (>1.5 standard deviations).

Ford et al. "We define a flash drought event in the USDM record as three category or more increase in drought se(2015) V verity over 8 or less weeks." (p. 9793)

Ford and Flash Drought is when "the pentad-average 0-40 cm soil moisture percentile at a station declines from at L a b o si e r or above the 40th percentile to at or below the 20th percentile in 4 pentads or less." (p. 417) (2017)

Park et al. Examined three satellite-based drought indices (details given in the paper):

(2018) 1) The scaled drought condition index (SDCI)

2) Microwave integrated drought index (MIDI)

3) Very short-term drought index (VSDI),

When any of these three indices dropped below 0.4 for even only one pentad ( 5 day period), the authors considered this a "dry period." While the authors did not define "flash drought," they conclude that the VSDI would be good for identifying "flash droughts caused by a rapid rate of intensification." 


\section{APPENDIX 2 CONTINUED}

Koster et al. Based on Ford and Labosier (2017) definition but with the following additional constraints:

(2019) 1) "A drought event has to lead to at least a nominal reduction in ET and thereby reflect some moisture stress on the land system...The 'nominal reduction' enforced here focuses on ET in the 20 days prior and in the 20 days after the 20-day soil moisture reduction period-ET in the prior period must lie at or above four-fifths of the climatological mean value for that time of year..., and ET in the latter period must lie at or below three-fifths of the climatological mean value for that later time of year."

2) "Independence of drought events is ensured by not allowing identified drought events...to overlap in time."

3) "The final constraint is that the climatological ET during the 20-day soil moisture reduction period lies above $0.5 \mathrm{~mm} /$ day. This condition is imposed because ... soil moisture percentile in dry regions is overly sensitive to meteorological drivers." (p. 1245)

Christian et Based on the principles outlined in (Otkin et al. 2018a):

al. (2019a) The data used include pentad values of Standardized Evaporative Stress Ratio:

$\mathrm{SESR}=\mathrm{ET} / \mathrm{PET}$ which is standardized for each grid point and pentad using the z-score minus the mean and the difference divided by the standard deviation.

In this methodology, flash drought events are required to have:

1) a minimum length of five SESR changes ( $\triangle \mathrm{SESR}$ ), equivalent to a length of six pentads (30 days);

2) a final SESR value below the 20th percentile of SESR values;

3) pentad-to-pentad changes toward drought development:

a) $\triangle$ SESR must be at or below the 40th percentile between individual pentads, and

b) no more than one $\triangle$ SESR above the 40th percentile following a $\triangle$ SESR that meets criterion 3a;

4) development through the entirety of the flash drought event...[i.e.] the mean change in SESR during the entire length of the flash drought must be less than the 25 th percentile of the climatological changes in SESR for that grid point and time of year.

Referenced by Christian et al. (2019b); Basara et al. (2019)

Chen et al. "[W]e define a flash drought event as a drought event with greater than or equal to two categories degra(2019)

Yuan et al. Flash Drought is identified when "the pentad (5 days) mean root-zone (top $1 \mathrm{~m}$ ) soil moisture decreases (2019) from above 40th percentile to 20th percentile, with an average decline rate of no less than $5 \%$ in percentile for each pentad...if the declined soil moisture rises up to 20 th percentile again, the drought terminates... the drought should last for at least 3 pentads (15 days)." (p. 2)

Liu et al. A drought event (of any kind) is identified when the soil moisture falls below the 40th percentile, and at (2020a) some point, within the drought event the soil moisture must fall below the 20th percentile (as in Ford and Labosier 2017).

A flash drought event is identified using a Rate of Intensification index (RI), which is the rate of change in soil moisture percentiles (P) per week. RI is measured during the onset-development phase of any drought. A flash drought is defined as:

mean $\mathrm{RI}>6.5 \mathrm{P} /$ week, or

$\max \mathrm{RI}>10 \mathrm{P} /$ week

Referenced by Liu et al. (2020b)

Pendergrass - Flash drought definition 1 (applications: international operations, prediction, research): $50 \%$ inet al. (2020) crease in EDDI (toward drying) over two weeks, sustained for at least another two weeks

- Flash drought definition 2 (application: US operations): two-category change in the U.S. Drought Monitor (USDM) in 2 weeks, sustained for at least another 2 weeks 
APPENDIX 2 CONTINUED

Noguera et Using the Standardised Precipitation Evaporation Index (SPEI; Vicente-Serrano et al. 2010), they stated:

al. (2020) "...the criteria selected to record the occurrence of a flash drought were:

1. A minimum length of 4 weeks in the development phase.

2. A $\triangle \mathrm{SPEI}$ value equal to or less than -2 z-units.

3. A final SPEI value equal to or less than -1.28 z-units." (p. 157)

APPENDIX 3. List of flash drought definitions that consider only short-term drought events, in chronological order

Reference Short-duration criteria

Hunt et al. "...a severe, short-term event characterized by moisture deficits and abnormally high temperatures...a

(2009) flash drought is the result of a synoptic meteorological pattern where potential ET greatly exceeds precipitation for a period no less than 3 weeks such that available water in a previously moist $(0-50 \mathrm{~cm})$ soil profile decreases by more than 50\%." (p. 757)

Referenced by: Mozny et al. (2012); Mo and Lettenmaier (2015); Krueger et al. (2015); Sanchez et al. (2016)

Mo and Heat wave flash droughts:

Lettenmaier $\mathrm{T}_{\text {air }}$ anomaly $>$ one standard deviation computed from the base period for that pentad,

(2015) $\quad$ ET anomaly $>0$, and

Soil Moisture \%ile $<40$.

Referenced by Mo and Lettenmaier (2016); Zhang et al. (2017); Koster et al. (2017); Rupp et al. 2017; Wang and Yuan (2018); Poshtiri et al. (2018); H. Zhang et al. (2019); Kim et al. 2019; Ran et al. (2020); Zhang et al. (2020)

Mo and Precipitation deficit flash drought:

Lettenmaier $\mathrm{T}_{\text {air }}$ anomaly $>$ one standard deviation;

(2016) $\quad$ ET anomaly $<0$,

Precip \%ile $<40 \%$

Applies only to grid points with pentad Precip climatology greater than $0.2 \mathrm{~mm} /$ day to distinguish P-deficit flash droughts from monsoon onset conditions.

Referenced by Zhang et al. (2017); Wang and Yuan (2018); Cook et al. (2018); Ran et al. (2020); Zhang et al. (2020)

Zhang et al. Adapted from Mo and Lettenmaier $(2015,2016)$

(2017) For each grid and pentad:

- a Heat Wave Flash Drought event is defined as the conditions under which the maximum temperature anomaly is greater than one standard deviation, the evapotranspiration anomaly is in positive phase, and the soil moisture percentile is lower than $40 \%$;

- a Precipitation Deficit Flash Drought event is defined by maximum temperature anomaly greater than one standard deviation, evapotranspiration anomaly in negative phase, and precipitation percentile below $40 \%$.

Referenced by Zhang et al. (2018); Li et al. (2020b)

Yuan et al. For each grid point and each pentad, a flash drought is defined as pentad-mean surface air temperature

(2018) anomaly is larger than one standard deviation, the percentile of target pentad-mean soil moisture is lower than $40 \%$, and the soil moisture percentile of target pentad is at least $10 \%$ lower than the preceding pentad. 


\section{APPENDIX 3 Continued}

Wang and Adapted from Mo and Lettenmaier $(2015,2016)$

Yuan (2018) Defined two types of flash drought:

(1) FD Type I : $\mathrm{T}_{\text {ano }}>\mathrm{T}_{\text {std }}, \mathrm{ET}_{\text {ano }}>0, \mathrm{q}\left(\theta_{\text {pentad }}\right)<30 \%$

(2) FD Type II : $\mathrm{T}_{\text {ano }}>\mathrm{T}_{\text {std }}, \mathrm{ET}_{\text {ano }}<0, \mathrm{q}\left(\theta_{\text {pentad }}\right)<30 \%$

Where:

$\mathrm{T}_{\text {ano }}\left({ }^{\circ} \mathrm{C}\right)=$ anomaly for the pentad-mean surface air temperature

$\mathrm{T}_{\text {std }}\left({ }^{\circ} \mathrm{C}\right)=$ standard deviation of the $\mathrm{T}_{\text {ano }}$ time series

$\mathrm{ET}_{\text {ano }}(\mathrm{mm} / \mathrm{d})=$ anomaly for the pentad-mean ET

$\mathrm{q}\left(\theta_{\text {pentad }}\right)=$ pentad-mean soil moisture quantile values $(\%)$

M. Zhang et This definition was created specifically for Shanchuan town, Anji County, Zhejiang Province, China, al. (2019) based on the local seasonality and climatology of rainfall at that location. It provides an example of a locally adapted definition of flash drought.

"A flash-drought event is defined as when the monthly [July or August] rainfall is less than 100 mm." (p. 2)

$\mathrm{Li}$ et al. While not using the term "flash drought" this paper references other flash drought papers to define "... (2020c) short-term droughts lasting a few weeks or even days (Mo and Lettenmaier 2015, 2016; Ford et al. 2015; Otkin et al. 2015, 2016, 2018).’(p. 892)

Using the standardized antecedent precipitation evapotranspiration index (SAPEI) this paper defines a "short-term drought" during the growing season (April-September) as:

1) grid points with daily SAPEI $<-1$

2) The area with SAPEI $<-1$ covers at least $1.6 \%$ of the study region

3) Drought patches that overlap from one day to the next were considered one event

4) The total event lasts for $2-4$ weeks

APPENDIX 4. LIST OF FLASH DROUGHT DEFINITIONS THAT REQUIRE A FLASH DROUGHT EVENT TO HAVE BOTH A RAPID-ONSET AND A SHORT-DURATION.

Reference

Li et al. (2020a)

\section{Rapid-onset and short-duration criteria}

Using a standardized evapotranspiration deficit index (SEDI)

flash drought identification follows three criteria:

- The duration is longer than five pentads but shorter than twelve pentads.

- The instantaneous intensification rate of the cumulative SEDI is at or below the $25 \%$ of cumulative distribution frequency of the change in the cumulative SEDI during flash drought development.

- Average instantaneous intensification rate during flash drought development phase is at or below the $40 \%$ of cumulative distribution frequency of the change in the cumulative SEDI during flash drought development.

\section{APPENDIX 5. List of indicator or indicator-types used in each flash drought definition.}

\begin{tabular}{cc}
\hline \hline Reference & Indicator Used \\
\hline Noguera et al. (2020) & SPEI \\
Pendergrass et al. (2020) & EDDI \\
Li et al. (2020a) & US Drought Monitor \\
\hline Li et al. (2020c) & Evapotranspiration \\
Liu et al. (2020a) & Precipitation \\
Koster et al. (2019) & Evapotranspiration \\
& Soil moisture \\
\hline
\end{tabular}


APPENDIx 5 Continued

\begin{tabular}{|c|c|}
\hline Yuan et al. (2019) & Soil moisture \\
\hline M. Zhang et al. (2019) & Precipitation \\
\hline Christian et al. (2019a) & Standardized Evaporative Stress Ratio: ESR $=$ ET $/ \mathrm{PET}$ \\
\hline Chen et al, (2019) & US Drought Monitor \\
\hline Wang and Yuan (2018) & $\begin{array}{l}\text { Air temperature } \\
\text { Evapotranspiration } \\
\text { Soil moisture }\end{array}$ \\
\hline Park et al. (2018) & $\begin{array}{l}\text { Three satellite-based drought indices use the combinations of the following data } \\
\text { - Land surface temperature } \\
\text { - Normalized difference vegetation index } \\
\text { - Tropical Rainfall Measuring Mission precipitation } \\
\text { - Soil moisture }\end{array}$ \\
\hline Yuan et al. (2018) & $\begin{array}{c}\text { Air temperature } \\
\text { Soil moisture }\end{array}$ \\
\hline Ford and Labosier (2017) & Soil moisture \\
\hline Zhang et al. (2017) & $\begin{array}{c}\text { Air temperature } \\
\text { Evapotranspiration } \\
\text { Soil moisture } \\
\text { Precipitation }\end{array}$ \\
\hline Mo and Lettenmaier (2016) & $\begin{array}{l}\text { Air temperature } \\
\text { Evapotranspiration } \\
\text { Precipitation }\end{array}$ \\
\hline Mo and Lettenmaier (2015) & $\begin{array}{l}\text { Air temperature } \\
\text { Evapotranspiration } \\
\text { Soil moisture }\end{array}$ \\
\hline Ford et al. (2015) & US Drought Monitor \\
\hline Anderson et al. (2013) & $\begin{array}{l}\text { Soil moisture changes } \\
\text { Evaporative Stress Index }\left(\mathrm{ESI}=\mathrm{ET} / \mathrm{F}_{\mathrm{ref}} \text {, where } \mathrm{F}_{\mathrm{ref}} \text { is a scaling flux }\right)\end{array}$ \\
\hline Hunt et al (2009) & $\begin{array}{c}\text { PET } \\
\text { precipitation } \\
\text { soil moisture }\end{array}$ \\
\hline
\end{tabular}

